\title{
Por um sangue bandeirante: Pacheco e Silva, um entusiasta da teoria eugenista em São Paulo*1
}

Lia Novaes Serra*2

lanni Régia Scarcelli*3

\begin{abstract}
$O$ intuito deste artigo foi o de analisar as contribuições do médico Antônio Carlos Pacheco e Silva para a consolidação de uma psiquiatria de cunho eugenista, nas primeiras décadas do século XX, em São Paulo. Buscamos salientar também a influência do médico, e de outros integrantes da Liga Paulista de Higiene Mental (LPHM), na divulgação de teorias racistas para a exclusão social de menores denominados de "anormais". Para tanto, utilizamos parte do material do acervo do Museu Histórico Prof. Carlos da Silva Lacaz, da Faculdade de Medicina da Universidade de São Paulo - USP. Como conclusão, percebemos que a ciência eugênica, adaptada para as condições locais, serviu para a psiquiatria paulista, desse período, justificar as desigualdades sociais pelo discurso da biologia e legitimar práticas de internação de crianças, que por sua constituição genética obstruiriam a formação de uma "raça paulista".
\end{abstract}

Palavras-chave: História da psiquiatria, eugenia, Hospital do Juquery, infância

${ }^{* 1}$ Este artigo é fruto da dissertação de mestrado: Serra, Lia Novaes (2011). Infância perdida: a concepção de menores anormais na obra de Pacheco e Silva. 2011. 150p. Dissertação (mestrado em Psicologia Social). Universidade de São Paulo. Sob a orientação de Ianni Régia Scarcelli.

*2 Universidade de São Paulo - USP (São Paulo, SP, Brasil)

${ }^{* 3}$ Universidade de São Paulo - USP (São Paulo, SP, Brasil) 


\section{Introdução}

Trata-se, neste artigo, de compreender as ressonâncias do trabalho do psiquiatra Antônio Carlos Pacheco e Silva para a constituição de uma psiquiatria de cunho eugenista, nas primeiras décadas do século XX, em São Paulo. Buscaremos analisar como os ideais eugênicos foram requeridos com o intuito de higienizar a população, sobretudo as crianças, que apresentavam ameaças ao projeto de sociedade almejado pela Liga Paulista de Higiene Mental, da qual Pacheco e Silva era integrante.

Os documentos pesquisados encontram-se no Museu Histórico Prof. Carlos da Silva Lacaz, da Faculdade de Medicina da USP, onde está boa parte do acervo pessoal do médico e professor Antônio Carlos Pacheco e Silva (1898-1988), psiquiatra paulista, autor de quase trinta livros e mais de 1.100 trabalhos de cunho cultural e científico. Essa figura paulistana teve grande importância para a institucionalização da psiquiatria no estado de São Paulo e, em seu percurso profissional, passou por instituições científicas, acadêmicas e também políticas.

Filho da plutocracia paulista, formou-se em Medicina pela Faculdade do Rio de Janeiro, em 1920, logo depois viajou para a Europa para complementar seus estudos. Na França, especializou-se em Neurologia e Psiquiatria pela Faculdade de Medicina de Paris. Também trabalhou na Clínica Charcot, localizada no Hospital de Salpêtrière, com o professor Pierre Marie. Estagiou na Suíça com Bleuler e Manokow, depois esteve na Alemanha onde acompanhou o trabalho de Kraepelin.

Quando retornou ao Brasil, parte de seus conhecimentos foram aplicados no Hospital do Juquery, onde teve a função de diretor após a saída de seu professor, Franco da Rocha. O Juquery, nesse momento, servia como palco de uma psiquiatria experimental que buscava solucionar as dificuldades enfrentadas pelo crescimento da cidade de São 


\section{HISTÓRIA DA PSIQUIATRIA}

Paulo. Franco da Rocha, primeiro diretor da instituição, almejava compatibilizar o problema da ordem urbana com o uso do cientificismo psiquiátrico nesse local também denominado de hospício "novo". O termo era utilizado para distinguir sua proposta de tratamento da adotada nos ditos "velhos hospícios", caracterizados como depositários de loucos. Segundo esse psiquiatra, o "novo" espaço asilar tinha vocação para cura e regeneração (Cunha, 1988).

Franco da Rocha dedicou sua vida à instituição e, quando se viu cansado e doente, em 1923, escreveu uma carta de indicação ao posto de diretor do Hospício ao Governador do Estado. Nesse documento, registrava sua vontade de deixar a Antônio Carlos Pacheco e Silva, seu aluno dileto, a chefia do Juquery: "Procurei um homem moço, correto, de moral irrepreensível e grande estudioso, cientista por temperamento e capaz de sacrificar-se por amor à ciência" (apud Camargo, 1978, p. 13).

Pacheco e Silva recebe o cargo no momento em que o alienismo estava em decadência no Brasil, as práticas psiquiátricas estavam voltadas para fora dos hospícios e as teorias da eugenia ocupavam o centro da orientação assumida pela medicina. Aos 25 anos, assumiu a direção do Hospital do Juquery, de 1923 a 1937. Em 1930, auxiliou na construção da Assistência Geral dos Psicopatas do Estado de São Paulo. Também dedicou-se à docência na Faculdade de Medicina da Universidade de São Paulo, na Escola Paulista de Medicina, na Escola de Sociologia e Política de São Paulo e na Faculdade de Direito da Universidade de São Paulo.

\section{A ciência eugênica entrelaçada ao meio médico}

Desde o final do século XIX, a teoria eugenista adentrava massivamente em países como Alemanha, França, Dinamarca, Áustria, Bélgica, Estados Unidos. Na América Latina também encontramos registros de sua influência no Peru, Argentina e Brasil. Aqui, a classe médica e a elite intelectual, que circulavam pelos congressos internacionais, trouxeram na bagagem as "inovadoras" ideias que surgiam a partir do uso do conhecimento sobre a hereditariedade para explicar o "aperfeiçoamento" da espécie humana.

A teoria eugenista, que fundamentava-se nos estudos de Darwin e Galton, propunha que as "raças" deveriam permanecer definidas, sem miscigenação, elevando a qualidade física e intelectual das raças "puras". No Brasil, um país de base miscigenada, a eugenia como ciência facilitou a intelectualidade brasileira a justificar as crises das primeiras décadas do regime republicano que se defrontava com a abolição da escravatura, o êxodo rural e a imigração europeia (Costa, 2007).

Cabe esclarecer que o termo "raça", nesta pesquisa, tem o sentido que the deram as ciências médicas no debate proposto para "biologizar" as categorias 
populacionais. Segundo António Sérgio Guimarães (2003), categoria "raça" foi criada pelas ciências biológicas e pela antropologia física para classificarem-se as subespécies humanas, assim como as animais. De acordo com essa classificação, algumas espécies seriam mais desenvolvidas intelectual, física e moralmente, justificando a hierarquização de certos grupos identitários e, em seus piores dias, favorecendo verdadeiros genocídios.

Em relação à eugenia, é necessário dizer que, em seu conjunto de ideias, foi compreendida de distintas maneiras pelos intelectuais brasileiros. Para Pacheco e Silva e os psiquiatras da Liga Paulista de Higiene Mental, a eugenia definia-se como um programa de ações que facilitaria a implementação de normas sociais na população. Essas ações eram divididas em três frentes: as iniciativas de caráter mais profilático, denominadas como eugenia preventiva, que tinha como intuito combater os vícios como o álcool e o tabaco; a chamada eugenia positiva que abrangia a educação higienista que incentivava os bons hábitos, a atividade física e intelectual; e as ações de caráter mais restritivo, nomeada como eugenia negativa que partia para as esterelizações nos "degenerados", proibia os matrimônios aos indivíduos "anormais" e controlava a imigração dos "inaptos” (Kehl, 1919).

Para Souza (2008), a aproximação com os modelos de eugenia "preventiva" e "positiva" que encontravam na pobreza, na doença e nos ambientes "disgênicos" as principais questões a serem tratadas não impediram que os eugenistas brasileiros se ocupassem com a composição racial nacional. A ideia proposta pelo psiquiatra Renato Kehl ${ }^{1}$ e pelos psiquiatras da LBHM era a de uma "regeneração racial" que não obstruísse o valor "eugênico" da mestiçagem brasileira, evitando, assim, o fracasso de um país previamente mestiço.

Antenado com as ideias da eugenia negativa, Pacheco e Silva segue caminho semelhante ao de Kehl ao mostrar-se de acordo com as diretrizes mais radicais tomadas pelos europeus, como por exemplo para tratar as doenças mentais de origem hereditária, que deveriam ser "impedidas da propagação de células sexuais taradas pela esterilização" (Pacheco e Silva [ca. 1937], p. 5, grifo nosso) ao mesmo tempo em que prevê a possibilidade de constituição de uma "raça" brasileira que atenda aos ideais de civilidade.

O debate sobre uma identidade nacional racial também aparece no discurso do psiquiatra como paraninfo da turma de 1938 da Faculdade de Medicina da

${ }^{1}$ Sobre a participação de Renato Kehl no movimento eugenista brasileiro, cf. Souza, V. (2006). A política biológica como projeto: a "eugenia negativa" e a construção da nacionalidade na trajetória de Renato Kehl (1917-1932). 
Universidade de São Paulo, no qual Pacheco e Silva (1939) aconselha aos novos médicos que não descuidem dos problemas étnicos do país, adquiridos pela catastrófica política de imigração, e enfatiza a política eugênica como saída para a melhoria da genética brasileira, aproximando-se as diretrizes proclamadas da eugenia negativa.

A higiene da raça, já o sabeis, repousa sobretudo em medidas eugênicas: uma raça é tanto melhor quanto maior for o número de famílias eugênicas, isto é, de componentes hereditariamente bem dotados. (...) A indiferença pelos problemas raciais, a inobservância das leis biológicas, o desprezo pela experiência antroposociológica se fazem sentir cedo ou tarde sobretudo nas nações novas, com incalculáveis prejuízos para a coletividade. (pp. 30-32)

De acordo com Marques (1994), o discurso racial era utilizado para diferenciar a população e ressaltar a periculosidade das classes pobres. Ao mesmo tempo em que criava um ideal racial para os brasileiros, apontava o embranquecimento e todo o arsenal de intervenções genéticas como saída.

O caráter técnico-científico desfrutado pela eugenia como ciência do aperfeiçoamento da raça, portanto capaz de intervir sobre a população para constituí-la, excluí-la ou conformá-la, conferia-lhe o poder de costurar instâncias constitutivas do social as quais nem a higiene, nem a filantropia, nem a educação, isoladamente, tinham sido capazes de articular. Tratava-se de um discurso integrador das estratégias de controle sobre o sexo que não se impunham através da lei mas por meio do poder político de gerar e gerir a vida da população e da cidade, decorrendo daí a possibilidade de progresso biológico e social. (p. 41)

A disseminação dos princípios eugenistas no Brasil levou a criação da primeira sociedade brasileira de eugenia, fundada em 1918, em São Paulo, por Kehl, com o apoio do diretor da Faculdade de Medicina de São Paulo, Arnaldo de Vieira Carvalho. Denominada como "Sociedade Eugênica de São Paulo" tinha 140 membros, dos quais a maior parte integrava a elite médica da cidade. A entidade durou cerca de um ano, embora tenha recebido positiva aceitação entre a imprensa e os médicos, a mudança de Kehl para o Rio de Janeiro, em 1919, parece ter abalado a permanência da associação.

\section{Uma "raça" de gigantes: é São Paulo dos bandeirantes}

Em São Paulo, após a saída de Kehl, Pacheco e Silva emerge como figura relevante para a disseminação dos princípios da eugenia. Num contexto em que o Estado crescia brutalmente, o projeto de modernização impunha novos padrões de 
sociabilidade e esperava-se substituir a imagem do paulistano doente por um Jeca Tatu higienicamente restaurado. ${ }^{2}$

Na década seguinte, em 1930, as campanhas de saúde pública tiveram lugar privilegiado na comunicação com a população. Jornalistas, juristas, médicos, literatos, cartunistas etc. envolveram-se em projetos diversos para produzir e propagar campanhas de saúde pública com a finalidade de constituir uma população "aperfeiçoada". É assim que, por meio da inspeção e da vigilância sanitária, os médicos adentraram o cotidiano das pessoas, procuravam prevenir ou tratar doenças, ao mesmo tempo em que impunham novos parâmetros de conduta, disciplina e normatização das características físicas (Machado et al., 1978).

Para Pacheco e Silva, havia um projeto de nação que se pautava no enaltecimento da linhagem genética e que poderia ter como alvo a ossada de um bandeirante. Em seus pressupostos, os paulistas deveriam se vangloriar de estar à frente do país, com um padrão de "raça" mais elevado. Professava Pacheco e Silva (1933) que, apesar de os tempos terem mudado, "a raça permanece intacta, os bandeirantes lutam sempre para engrandecer a Pátria e implantar os marcos da civilização, seguindo as diretrizes dos seus antepassados" (p. 4).

Decerto, existem entre os pesquisadores da saúde diferentes concepções sobre a proliferação do mito bandeirante nos discursos políticos de São Paulo. Para Pinto (2001), por exemplo, havia também uma tendência nacionalista que se contrapunha à corrente dos que elegiam o bandeirante como figura proeminente para os paulistas. Parte da elite intelectual que compartilhava esse discurso almejava acompanhar o ritmo acelerado das fábricas e aderir à industrialização e à urbanização sem preservar a imagem romântica dos bandeirantes como verdadeiros heróis nacionais. Segundo a autora, esse grupo foi denominado como os "modernistas".

No entanto, em nossos achados, vemos que grande parte dos projetos médicosanitários elegeram o bandeirante como símbolo da grandiosidade do estado. Aliás, desde o final do século XIX, diversas produções científicas já fundamentavam o traço heroico do bandeirante paulista como um dos pilares para o desenvolvimento da região. A superioridade da raça paulistana assentava-se no mito da "raça dos gigantes", fundado por Saint-Hilaire, que com sua proeza de desbravador tal qual os bandeirantes levaria à modernização e ampliação das cidades brasileiras (Mota, 2005).

Em conferência no Clube Piratininga, Pacheco e Silva relembra ardente espírito paulista, dos "gloriosos" combatentes de 1932, que lutaram por princípios nobres,

${ }^{2}$ Para ler mais sobre o personagem de Monteiro Lobato e o higienismo, cf. Moraes, P. (1997). O Jeca e a cozinheira: raça e racismo em Monteiro Lobato. 


\section{HISTÓRIA DA PSIQUIATRIA}

combatendo o despotismo que se abatera sobre a Pátria. Disse que se desejava voltar a falar a língua "pura" do tempo das bandeiras, porque fora sob sua inspiração que o estado crescera e resistira a todos os que não puderam suportar o espírito paulista.

Escolhi muito propositadamente este Clube para dizer algumas palavras repassadas de sinceridade, porque sei que elas serão aqui bem interpretadas, pois os que me ouvem são verdadeiros paulistas, pelo sangue ou pelo coração, os quais representam a encarnação viva e legítima do espírito e do caráter da nossa gente, que soube resistir heroicamente às tentativas feitas para quebrantar a alma de São Paulo, para denegrir as nossas tradições, para abalar a mística legada pelos nossos antepassados, para amolecer a fibra bandeirante, para negar o nosso papel na formação social brasileira. (Pacheco e Silva, 1947, p. 7).

Em um texto anterior, Pacheco e Silva homenageia os ancestrais bandeirantes pela força legada aos combatentes da Revolução de 32, que elevaram a "raça paulista". E, simultaneamente, vê-se a afirmação da aplicabilidade dos princípios da eugenia sobre a população:

As imagens que os cérebros infantis plasmaram quando São Paulo inteiro vibrava; os quadros que a mocidade da nossa terra deparou nas trincheiras durante a campanha; os martírios e o estoicismo da mulher paulista; o esforço sobre-humano e a capacidade sem par posta à prova por todas as forças vivas de Piratininga, ficarão gravados para sempre na memória de todos nós, como a demonstração mais expressiva da vitalidade de uma raça. (...) A homenagem mais expressiva e digna que se poderá render aos que tombaram na defesa dos nossos ideais é a de se levantar em holocausto à sua memória uma nova e pujante geração, cimentada por um mesmo ideal comum, capaz de zelar pelas nossas gloriosas tradições e reafirmar os predicados incomparáveis da raça. (Pacheco e Silva [ca. 1943], p. 2)

As "gloriosas tradições" de que fala o texto remetem a essa imagem mítica do bandeirante fundador e desbravador das terras paulistas. Pode-se pensar que havia um ideal de civilidade a ser cumprido pelas gerações seguintes. Com o apoio do mito da "raça" paulista, cientificamente fundamentado pela eugenia, a população teria de corresponder ao ideal proposto por boa parte dos médicos paulistas. No entanto, como já dissera Schwarcz (1993), o trabalho de constituição de uma nação passou por diversos impasses e ambiguidades, de que se destacou a miscigenação, característica fundamental da população.

\section{Onde estão as crianças? A privação de uma infância}

Uma saída para a constituição de uma "raça paulista" era a implementação de políticas que atuassem sobre os indivíduos e as coletividades que alcançassem 
o branqueamento, a disciplina e a normalização. Nesse sentido, certos médicos propunham que o Estado detivesse formas de controle cada vez mais centralizadoras, como Pacheco e Silva que sugeriu que a Constituição Brasileira ganhasse novas emendas, incumbindo a União de seguir os parâmetros da higiene mental e da eugenia para cuidar de sua população (Pacheco e Silva, [ca. 1934], p. 2).

Vale ressaltar que entre os pesquisadores da história da medicina, não é unânime a proposição de que o poder público, em contrapartida, absorveu o discurso médico a ponto de torná-lo central em suas diretrizes políticas. O sociólogo José Ferreira Antunes (1998), por exemplo, relativiza essa visão comumente aceita de que a medicina direcionava a ação governamental. Por outro lado, encontramos em nossas fontes de pesquisa argumentos que fortalecem a ideia de que certos médicos detinham, sim, representação política suficiente para a proposição e consolidação de políticas públicas. Sobretudo, porque muitos médicos ocupavam também cargos políticos no governo federal, estadual e municipal.

Pacheco e Silva, por exemplo, trabalhou como deputado na Assembleia Nacional Constituinte, em 1934, e deputado na Assembleia Constituinte e Legislativa de São Paulo, em 1935, além da docência. O médico Savino Gasparini, ${ }^{3}$ que era membro da equipe técnica do Serviço de Propaganda e Educação Sanitária do Ministério da Educação e Saúde, viabilizou projetos de cunho eugenista no governo Vargas. E teríamos mais tantas outras ilustrações a respeito dessa transição entre o meio médico e governamental no Brasil da década de 1930.

E, em geral, as políticas de Estado, que seguiam o parâmetro da higiene mental e da eugenia, tinham como enfoque a criança por acreditar que era a via mais fácil de prevenir os conflitos e os desajustamentos. Ao regular o hábito de vida dos pequenos, poderiam acompanhar e intervir desde a concepção de uma gravidez até a vida adulta, aproveitando, na infância, esse período em que a "alma é ainda dócil" e reprimir-lhe qualquer gesto de desonestidade é mais simples (Ramos, 1939).

As diretrizes políticas para essa parcela da população davam prioridade à internação como medida de atenção, especialmente aos provenientes de classes sociais mais baixas. O Decreto 24.794, de 1934, por exemplo, permitia a exclusão social e o agrupamento institucional de crianças que representavam a inutilidade, a anormalidade, a periculosidade e a doença moral. Tal política de internação, filantrópica privada ou governamental, visava a correção desses menores "anormais".

$\mathrm{O}$ argumento central em favor do tratamento de internação para os "menores anormais" era que a prevenção e as medidas educativas corretivas diminuiriam os

${ }^{3}$ Cf. Gonçalves, M. (2011, jan/jun.). Educação, Higiene e Eugenia no Estado Novo: as palestras de Savino Gasparini transmitidas pela Rádio Tupi (1939-1940). 


\section{HISTÓRIA DA PSIQUIATRIA}

gastos do Estado com a construção de novos presídios. E Pacheco e Silva tinha convicção dessa proposta já que estimava que metade dos presidiários apresentavam anomalias neuropsíquicas que poderiam ter sido evitadas pela assistência precoce e o tratamento adequado (Pacheco e Silva [ca. 1938]).

Assim, Pacheco e Silva explicava que quanto mais cedo fossem retirados, menores perigos ofereceriam à sociedade. Ao mesmo tempo, seria possível realizar nesses menores estudos que trouxessem novos achados à "personalidade delinquente". O método de estudo da "personalidade delinquente" era pautado no critério da "decomposição sintética da personalidade", a qual ajudaria a determinar os fatores genealógicos, biográficos e sociológicos que constituíram a formação da "personalidade" e promoveram a "deformação" do indivíduo (Pacheco e Silva, 1941).

A delinquência seria consequência das patologias específicas de cada menor, e o crime seria compreendido pelas disfunções "anormais" do corpo, fosse por herança biológica, fosse pelas condições de vida, e não como reflexo de estruturas econômicas, sociais e políticas (Zuquim, 2002).

O debate sobre a criminalidade ajudou Pacheco e Silva a justificar os novos investimentos para a prevenção e a cura da delinquência dos "menores anormais" e também dos "abandonados". Novas instituições deveriam ser criadas para tratar e investigar todas as possíveis causas das "anormalidades". Como exemplo dessa preocupação, tem-se a construção, em 1929, da Escola Pacheco e Silva, para menores "anormais", no Hospital do Juquery.

Desse modo, pode-se perceber que as "anormalidades" eram justificadas por diversas possibilidades que passavam pelo âmbito social e individual. No entanto, sobressaiu o uso das categorias psicológicas ${ }^{4}$ como modelo de análise à infância "anormal", isso se deve, a nosso ver, às justificativas que a classe médica buscava encontrar no desenvolvimento da criança os índices e padrões normativos. O exame empreendido em cada menor buscava investigar todas as variáveis possíveis. E o médico era o único capaz de conhecer a natureza da constituição psíquica do "anormal" e receitar o tratamento adequado.

(...) nem sempre é o estado somático de tais crianças indicativo da sua anormalidade; algumas há que não patenteiam qualquer estigma físico de degeneração, parecendo não se desviar do tipo normal da espécie e da sua raça. Em outras, porém, se deparam, desde logo, deformidades congênitas e perturbações patológicas que denunciam sua degeneração e explicam sua anormalidade psíquica. Em alguns

${ }^{4}$ As categorias psicológicas podem ser compreendidas, de acordo com Zuquim (2001, p. 11), como "as marcas de um discurso que ainda não se legitima como psicológico, mas que já traz a matriz de uma nova linguagem que se anuncia”. 
casos, bastaria para a perfeita classificação do colegial a observação demorada de um professor, ou professora, hábil, mas, na maioria deles, só o médico poderá dar a última palavra, estabelecendo o grau de anormalidade e traçando o programa de educação especial. (Moraes, 1927 apud Patto, 1999, p. 333).

De acordo com Pacheco e Silva, após a detecção de "anormalidade", havia ainda uma etapa difícil, que seria a caracterização do tipo de alteração presente no indivíduo. Essa caracterização se apoiava ora em critérios de classificação pautados na escala de Morel (debilidade mental, imbecilidade e idiotia), ora nos estudos de Ziehen, que introduziu o conceito de psicopatia (Pacheco e Silva [ca. 1938]). Ele acreditava ainda que critérios de classificação facilitariam a indicação da terapêutica mais eficaz no tratamento dos menores.

\section{Conclusões}

Buscamos discutir neste artigo as ressonâncias da ciência eugênica no trabalho prático e teórico do psiquiatra Antônio Carlos Pacheco e Silva, especialmente no que se refere às crianças denominadas de "anormais", no estado de São Paulo, na década de 1930. Vimos que suas convicções científicas estavam diretamente relacionadas a um conjunto de condições econômicas, sociais e políticas inscritas num processo histórico que modificou a direção do tratamento dessas crianças que não se adequavam aos parâmetros normativos eugenistas.

Percebemos que o aumento do contingente populacional nas cidades paulistas pressupunha, aos psiquiatras da LPHM, novas formas de ordenar e controlar a vida. Nesse sentido, amparados pelo caráter científico da higiene mental e da eugenia, ações profiláticas, preventivas e restritivas foram utilizadas de diversas formas com o intuito de "aperfeiçoar" a genética populacional.

Vimos como a ideia de uma raça "pura", tão utilizada em países europeus, precisou ser revista e adaptada às condições brasileiras. Se somos um país de miscigenados, essa característica não poderia fadar o fracasso brasileiro. Para evitar o descontentamento dos ideais de uma raça superior, a mistura racial foi bem aceita e encarada com certo otimismo. Para os psiquiatras da LPHM, se houvesse a miscigenação, em algumas décadas haveria o embranquecimento populacional.

Analisamos também como o mito de uma "raça paulista", herdeiro dos bandeirantes, povoou o imaginário da população. A reputação de um povo pioneiro e desbravador, que ampliou o território da nação em busca de ouro, foi explorada pelos dirigentes paulistas da Primeira República para conquistar espaço na política nacional. As elites paulistas creditavam ao "sangue nobre bandeirante" a responsabilidade pelo progresso e pelo desenvolvimento nacional (Mota, 2005). 


\section{HISTÓRIA DA PSIQUIATRIA}

Com o discurso da necessidade de constituir um projeto de excelência racial para o estado, a medicina eugenista capturou a infância. Diziam os médicos da Liga que o melhor remédio para curar uma população degenerada era a prevenção, e prevenção se faz na infância. Desse modo, o movimento da higiene mental percebeu que as crianças eram o foco privilegiado para a profilaxia. Infelizmente, vimos também que as diretrizes de tratamento para as crianças que não correspondiam a esse ideário eugenista era a reclusão social.

\section{Referências}

Antunes, J.F. (1998). Medicina, leis e moral: pensamento médico e comportamento no Brasil (1870-1930). São Paulo: Unesp.

Camargo, A.G. (1978). In: Sessão Solene na Associação Paulista de Medicina. 1, 1978. São Paulo. Homenagem ao Prof. Dr. Antônio Carlos Pacheco e Silva. p. 12-16.

Costa, J.F. (1979). Ordem médica e norma familiar. Rio de Janeiro: Graal.

Costa, J.F. (2007). História da psiquiatria no Brasil: um corte ideológico. $5^{\mathrm{a}}$ ed. Rio de Janeiro: Garamond.

Cunha, M.C.P. (1988). O espelho do mundo - Juquery a história de um asilo. $2^{\mathrm{a}}$ ed. São Paulo: Paz e Terra.

Gonçalves, M. (2011, jan/jun.). Educação, Higiene e Eugenia no Estado Novo: as palestras de Savino Gasparini transmitidas pela Rádio Tupi (1939-1940). Cadernos de História da Educação, 10(1).

Guimarães, A.S. (2003). Como trabalhar com "raça" em sociologia. In: Educ. Pesqui. (online). 29(1) [cited 2010-04-07], pp. 93-107 . Recuperado de: <http://www.scielo.br/ >. ISSN 1517-9702. doi: 10.1590/S1517-97022003000100008.

Kehl, R. (1919). Sociedade Eugênica de São Paulo. Jornal do Comércio, São Paulo, 4 abril 1919.

Kehl, R. (1947). A cura do espírito. $2^{\mathrm{a}}$ ed. Rio de Janeiro: Francisco Alves.

Machado, R. et al. (1978). Danação da Norma - Medicina Social e constituição da Psiquiatria no Brasil. Rio de Janeiro: Graal.

Marques, V. (1994). A medicalização da raça: médicos, educadores e discurso engênico. Campinas: Unicamp.

Moraes, P. (1997). O Jeca e a cozinheira: raça e racismo em Monteiro Lobato. Revista de Sociologia e Politica, Curitiba, 8, 99-112.

Moraes, E. (1927). Criminalidade da infância e da adolescência. Rio de Janeiro: Francisco Alves. pp. 53-54.

Mota, A. (2005). Tropeços da Medicina Bandeirante: medicina paulista, 1892-1920. São Paulo: Edusp. 
Mota, A., \& Schairaiber, L. (org.) (2009). Infância e Saúde - perspectivas históricas. São Paulo: Hucitec.

Pacheco e Silva, A.C. (1933a). A higiene mental nos tempos atuais. São Paulo: Oficinas gráficas do Juquery.

Pacheco e Silva, A.C. (1933b). A mulher paulista no atual momento brasileiro. Conferência realizada no salão Club Comercial. São Paulo.

Pacheco e Silva, A.C. (1941). A perícia da periculosidade criminal. Conferência realizada na Faculdade de Direito da Universidade de São Paulo. São Paulo, 28 outubro, 1941.

Pacheco e Silva, A.C. (ca.1929). Conferência proferida no I Congresso Brasileiro de Eugenia. Rio de Janeiro.

Pacheco e Silva, A.C. (1943). Contribuição da psiquiatria para o esclarecimento dos problemas criminológicos. In: Estudos Penitenciários (pp. 167-177) São Paulo: IMESP

Pacheco e Silva, A.C. (ca.1934a). Direito à saúde no Brasil. Acervo do Museu Histórico da FMUSP (mimeo), São Paulo, 1934.

Pacheco e Silva, A.C. (1939). Discurso pronunciado como paraninfo na cerimônia da colação de grau dos doutorandos da Faculdade de Medicina da Universidade de São Paulo. Revista dos Tribunais, São Paulo.

Pacheco e Silva, A.C. (1936). Importância da higiene mental na infância. Acervo do Museu Histórico da FMUSP (mimeo), São Paulo.

Pacheco e Silva, A.C. (ca.1937). Impressões do Congresso Internacional de Psiquiatria Infantil e Higiene Mental. São Paulo.

Pacheco e Silva, A.C. (1947). Instantâneo do momento brasileiro. Clube Piratininga. São Paulo. pp. 7-20.

Pacheco e Silva, A.C. (1938, $1^{\circ}$ e $2^{\circ}$ trim.). Seção de menores anormais do Hospital do Juquery. Arquivos do Serviço de Assistência a Psicopatas do Estado de São Paulo, III, 251-258.

Pacheco e Silva, A.C. (ca.1938). Tratamento e assistência aos menores anormais. Museu Histórico da FMUSP (mimeo), São Paulo.

Passetti, E. (2010). Crianças carentes e Políticas Públicas. In Priore, Mary Del (Org.). História das crianças no Brasil (7ª ed., pp. 347-375). São Paulo: Contexto.

Patto, M.H.S. Ciência e política na primeira República: Origens da Psicologia Escolar. In A. Jacó-Vilela, et al. (1999). Clio-psyché: histórias da psicologia no Brasil. Rio de Janeiro: Universidade do Estado do Rio de Janeiro.

Pinto, M.B. (2001). Urbes industrializada: o modernismo e a pauliceia como ícone da brasilidade. Revista Brasileira de História. [online]. 21(42) [cited 2010-09-28], 435-455.

Ramos, A. (1955). Saúde do espírito: higiene mental. 6a ed. Rio de Janeiro: Serviço Nacional de Educação Sanitária (Trabalho original publicado em 1939).

Reis, J.R.F. (2000, jun.). De pequenino é que se torce o pepino: a infância nos programas eugênicos da Liga Brasileira de Higiene Mental. História da Ciência Saúde-Manguinhos, 7(1), 135-57. 


\section{HISTÓRIA DA PSIQUIATRIA}

Schwarcz, L.K.M. (1993). O espetáculo das raças: cientistas, instituições e pensamento racial no Brasil - 1870-1930. São Paulo: Companhia das Letras.

Serra, L. (2011). Infância perdida: a concepção de "menores anormais" na obra de Pacheco e Silva (Dissertação de mestrado), Instituto de Psicologia da Universidade de São Paulo, São Paulo.

Souza, V. (2006). A política biológica como projeto: a "eugenia negativa” e a construção da nacionalidade na trajetória de Renato Kehl (1917-1932). (Dissertação de Mestrado em História das Ciências), Casa de Oswaldo Cruz, Fiocruz, Rio de Janeiro.

Souza, V. (2008, jul/dez.). Por uma nação eugênica: higiene, raça e identidade nacional no movimento eugênico brasileiro dos anos 1910 e 1920. Revista Brasileira de História da Ciência, Rio de Janeiro, 1(2), 146-166.

Zuquim, J. (2001). Infância e crime na história da psicologia no Brasil: um estudo de categorias psicológicas na construção da história da infância criminalizada na Primeira República. (Dissertação de mestrado), Instituto de Psicologia, Universidade de São Paulo, 2001.

Zuquim, J. (2002). "Pequenos psicopatas". Infância, criminalidade e loucura na Primeira República. In (Org.). Antunes, E.; Barbosa, L.; \& Pereira, F. Psiquiatria, loucura e arte: fragmentos de história brasileira. São Paulo: Edusp.

\section{Resumos}

A pure Bandeirante race: Pacheco e Ssilva, an enthusiast of the eugenist theory in São Paulo)

Our aim in this paper was to analyze the contributions of Antonio Carlos Pacheco e Silva in establishing a psychiatric approach that included eugenics in the early decades of the 20 century in São Paulo. We discuss the influence of psychiatrists and other members of the São Paulo Mental Hygiene League (Liga Paulista de Higiene Mental) on the dissemination of racist theories for the treatment of minors labeled as "abnormal." We observed material at the Professor Carlos da Silva Lacaz Museum of History, at USP. In conclusion, we show how the science of eugenics, adapted to local conditions, was useful for psychiatry in the attempt justify social inequalities through the discourse of biology and in the legitimation of practices of institutionalization of children who might which genetically thwart the formation of a "pure race of humans in the State of São Paulo."

Key words: History of psychiatry, eugenics, Juquery Hospital, childhood

(Pour un sang bandeirante: Pacheco e Silva, un enthousiaste de la théorie eugéniste à São Paulo)

Cet article examine les contributions du médecin Antônio Carlos Pacheco e Silva à l'établissement d'une psychiatrie basée sur l'eugénisme au début du XXe siècle à São 
Paulo. Nous cherchons à mettre en évidence l'influence du médecin et d'autres membres de la Liga Paulista de Higiene Mental (LPHM) (Ligue de São Paulo pour l'Hygiène Mentale) sur la diffusion des théories racistes pour l'exclusion sociale de mineurs classés comme "anormaux". Nous avons utilisé une partie du matériel du Musée Historique Prof. Carlos da Silva Lacaz de la Faculté de Médicine de l'Université de São Paulo (USP). Nous concluons que la science eugénique, adaptées aux conditions locales, a été utilisée par la psychiatrie de São Paulo de cette période pour justifier les inégalités sociales à travers le discours de la biologie et pour légitimer des pratiques d'internement d'enfants qui, étant donné leur constitution génétique, entravaient la formation d'une "race paulista".

Mots clés: Histoire de la psychiatrie, eugénie, Hôpital Juquery, enfance

(Por una sangre bandeirante: Pacheco e Silva, un entusiasta de la teoria eugenista en São Paulo)

Nuestro objetivo en este trabajo es analizar las contribuciones de Antônio Carlos Pacheco e Silva para el establecimiento de una psiquiatría con trazos de eugenesia en las primeras décadas del siglo XX, en São Paulo. Se destaca la influencia del médico y otros miembros de la Liga Paulista de Higiene Mental (LPHM) en la difusión de teorías racistas para la exclusión social de niños denominados de "anormales". Utilizamos parte de los materiales del Museo de Historia Profesor Carlos da Silva Lacaz de la Universidad de São Paulo. En conclusión, hemos visto que la ciencia eugenésica, adaptada a las condiciones locales, sirvió a la psiquiatría paulista de ese período para justificar las desigualdades sociales a través de un discurso de la biología y legitimar prácticas de hospitalización de niños que por su constitución genética obstruirian la formación de una "raza paulista".

Palabras claves: Historia de la psiquiatría, Eugenesia, Juquery Hospital, Niñez

(Der Wunsch nach "Landeroberer-Blut": Pacheco e Silva, ein begeisterter Anhänger der Theorie der Eugenetik in São Paulo)

Ziel dieses Artikels ist die Untersuchung der Beiträge des Arztes Antônio Carlos Pacheco e Silva zur Konsolidierung einer eugenistischen Psychiatrie, in den ersten Jahrzehnten der 20. Jahrhunderts in São Paulo. Wir heben hier auch den Einfluss dieses Arztes sowie anderer Mitglieder der Liga Paulista de Higiene Mental (LPHM) (Bund geistiger Hygiene von São Paulo), auf die Verbreitung rassistischer Theorien zum Ausschluss von so genannten "anormalen” Minderjährigen aus der Gesellschaft hervor. Dazu wird ein Teil des Materials aus dem Bestand des historischen Museums Prof. Carlos da Silva Lacaz, der Medizinischen Fakultät der Staatlichen Universität von São Paulo - USP verwendet. Als Schlussfolgerung wurde festgestellt, dass die eugenetische Wissenschaft an die lokalen Bedingungen angepasst und von der Psychiatrie in São 


\section{HISTÓRIA DA PSIQUIATRIA}

Paulo in dieser Epoche dazu genutzt wurde, die sozialen Unterschiede über den Diskurs der Biologie zu erklären und die Einlieferung von Kindern in Anstalten zu rechtfertigen, weil sie durch ihre genetische Beschaffung die Gestaltung einer reinen "paulistaner Rasse" im Wege standen.

Schlüsselwörter: Geschichte der Psychiatrie, Eugenik, Hospital do Juquery, Kindheit

Citação/Citation: Serra, L. N., \& Scarcelli, I. R. (2014, março). Por um sangue bandeirante; Pacheco e Silva, um entusiasta da teoria eugenista em São Paulo. Revista Latinoamericana de Psicopatologia Fundamental, 17(1), 85-99.

Editor do artigo/Editor: Profa. Dra. Ana Maria G. Raimundo Oda e Prof. Dr. Paulo Dalgalarrondo

Recebido/Received: 5.6.2013/ 6.5.2013 Aceito/Accepted: 25.8.2013 / 8.25.2013

Copyright: (C) 2009 Associação Universitária de Pesquisa em Psicopatologia Fundamental/ University Association for Research in Fundamental Psychopathology. Este é um artigo de livre acesso, que permite uso irrestrito, distribuição e reprodução em qualquer meio, desde que o autor e a fonte sejam citados / This is an open-access article, which permits unrestricted use, distribution, and reproduction in any medium, provided the original author and source are credited.

Financiamento/Funding: As autoras declaram não ter sido financiadas ou apoiadas / The authors have no support or funding to report.

Conflito de interesses/Conflict of interest: As autoras declaram que não há conflito de interesses / The authors declare that has no conflict of interest.

\section{Lia Novaes Serra}

Mestre em Psicologia Social e do Trabalho pelo Instituto de Psicologia da Universidade de São Paulo - USP (São Paulo, SP, Br).

Av. Prof. Mello Moraes, 1721

05508-900 São Paulo, SP, Br

e-mail: lia@versopsicanalise.com.br

\section{IANNi Régia Scarcelli}

Prof. Dra. do Departamento de Psicologia Social e do Trabalho do Instituto de Psicologia da Universidade de São Paulo - USP (São Paulo, SP, Br).

Av. Prof. Mello Moraes, 1721

05508-900 São Paulo, SP, Br

e-mail: iannirs@usp.br 